\title{
RESEARCHES ON WATERHYDRAULIC MOTOR
}

\author{
Franc Majdič* \\ Laboratory for fluid power and controls, Faculty of mechanical engineering, University of Ljubljna, Aškerčeva 6, \\ SI-1000 Ljubljana, Slovenia \\ * Corresponding author: Tel.: +386 14771 411; E-mail address: franc.majdic@fs.uni-lj.si
}

\begin{abstract}
Tribology has been recognized as a very important discipline in different branches of industry because almost every mechanical system has some moving parts. Due to the relative motion between these different mechanical parts, a variety of contacts are formed, and they are very often lubricated with oil. Environmental protection and ecological awareness are becoming increasingly important, which in turn has resulted in the shift to a low-carbon society, making water more interesting as a possible lubricant. On the one hand, water is less environmentally damaging as a lubricant than oil, but on the other hand, water has very poor lubrication properties, as its viscosity is 100 times lower than the viscosity of oil. These limitations might be overcome by appropriate surface engineering (e.g., diamond-like carbon, DLC). Tribological tests were performed in oil and water for two different contacts. Steel/steel and steel/DLC were investigated. DLC was recognized as a very promising solution, which ensures low friction and low wear. DLC was deposited on a real hydraulic part in an orbital hydraulic motor and tested under real industrial conditions. The overall efficiency of the hydraulic motor was measured.
\end{abstract}

Keywords: water hydraulics, orbital hydraulic motor, tribology, stainless steel, DLC coatings, efficiency

\section{INTRODUCTION}

Hydraulics is an important way of transferring power. Different fluids are used for the energy transfer from hydraulic pumps, through valves and pipelines to actuators. Nowadays, spilling harmful hydraulic fluids into the environment occurs frequently. Environmentally friendly alternative hydraulic fluids to replace the most commonly used mineral oils are bio-degradable fluids [1], ionic liquids [2] and water [3, 4]. Water hydraulics is still in the development phase [5]. A lot of different water-hydraulics components are missing. One of them is high-torque, slow-speed, gerotor hydraulic motors [6].

Researchers have tested the performance of water in various conditions [6,7]. Kano et al. [8] found that the coefficient of friction is low when tested for SS/DLC in water due to the favorable energy conditions in the contact. Ohana et al. [9] found that the coefficient of friction in a contact of stainless steel with DLC lubricated with water is lower than 0.1 .

\section{WATER AS A HYDRAULIC FLUID}

The most important properties of water as a hydraulic pressure medium are power transfer, lubrication, sealing, cooling, kinematic viscosity, compressibility, evaporation pressure, and air consumption. [10]. Power transfer is the basic function of a hydraulic fluid. A hydraulic pump transfers the mechanical energy to the hydraulics, which is transferred with the fluid through the hydraulic system to the actuators. Water has no significant difference in terms of power transfer compared to the most frequently used hydraulic mineral oil. Lubrication is an important property of hydraulic fluid as it reduces the friction and wear in the sliding contacts inside the hydraulic components. Water has very poor lubrication properties in the contacts of steel surfaces as it is generally used in oil hydraulics. The sealing connected to the kinematic viscosity of the fluid has an important role in the low-gap sliding contact inside of hydraulic components. Due to the significantly lower kinematics viscosity of water compared to hydraulic mineral oil, gaps in the water hydraulic components should be at least 
half the size. The kinematic viscosity of water is 55-times lower than that of mineral oil (ISO VG46 at $50{ }^{\circ} \mathrm{C}$ ). The cooling properties of water are significantly better than those of hydraulic mineral oil. The compressibility module of water is $2.1 \cdot 10^{5} \mathrm{MPa}$, this is $46 \%$ lower than for mineral hydraulic oil. Very important advantages of water are its availability in nature and its friendless to the environment (no danger of pollution). The most important properties of water with respect to being a hydraulic fluid are described in Table 1. Figure 1 shows the temperature dependence of the kinematic viscosity of water.

Table 1: Important parameters of water as a hydraulic fluid [10]

\begin{tabular}{ll}
\hline Water properties & Value \\
\hline Kinematics viscosity at $3^{\circ} \mathrm{C}$ & $1.6 \mathrm{~mm}^{2} / \mathrm{s}$ \\
Kinematics viscosity at $50^{\circ} \mathrm{C}$ & $0.55 \mathrm{~mm}^{2} / \mathrm{s}$ \\
Density at $50^{\circ} \mathrm{C}$ & $999.15 \mathrm{~kg} / \mathrm{m}^{3}$ \\
Compressibility & $2.4 \cdot 10^{9} \mathrm{~N} / \mathrm{m}^{2}$ \\
Evaporation pressure at & $0,12 \mathrm{bar}$ \\
$50^{\circ} \mathrm{C}$ & \\
Speed of sound at $20^{\circ} \mathrm{C}$ & $1480 \mathrm{~m} / \mathrm{s}$ \\
Specific heat at $20^{\circ} \mathrm{C}$ & $4390 \mathrm{~J} /\left(\mathrm{kg} \cdot{ }^{\circ} \mathrm{C}\right)$ \\
Useful temperature range & $3^{\circ} \mathrm{C}$ to $50^{\circ} \mathrm{C}$ \\
\hline
\end{tabular}

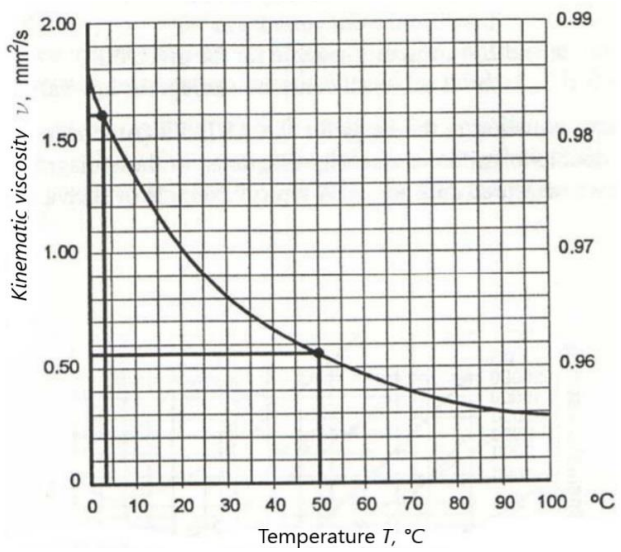

Figure 1: Kinematic viscosity of water as a function of temperature [10]

\section{GEROTOR HYDRAULIC MOTOR}

A specimen, high-torque, low-speed, hydraulic motor is shown in Figure 2 and Figure 3. The main parts of the motor are: rotor (1), rotor-ring (2), shaft (3), housing (4), valve plate (5), two conical bearings (6), upper (7) and lower (8) housing, static sealing (9) and shaft sealing (10). Figure 3 shows the three pressure $(\mathrm{P})$ and three return $(\mathrm{T})$ chambers and the rotation direction of the shaft. The rotation of the output shaft of the hydraulic motor is due to the pressure in the three pressure chambers $(\mathrm{P})$. The pressure tends to increase in the pressure chambers and thus the rotor rolls along the rotor ring.

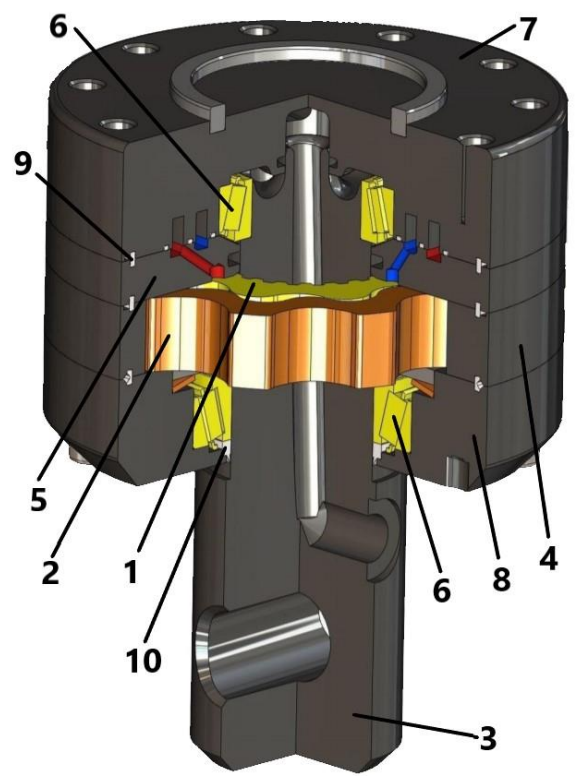

Figure 2: Cross-section of specimen - gerotor hydraulic motor

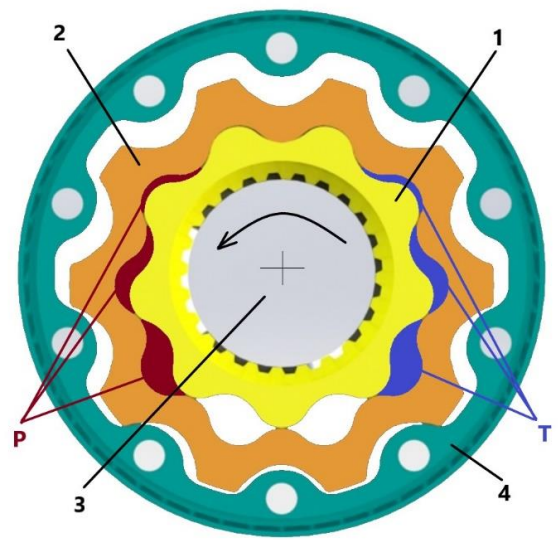

Figure 3: The most important parts of the gerotor 


\section{EXPERIMENTAL}

The gerotor hydraulic motor was developed in two ways: first the basic tribological material tests and then the water hydraulic tests.

\subsection{Tribological investigations}

Tribological tests of highly loaded surfaces lubricated once with the hydraulic mineral oil ISO VG 46 and second with distilled water were made on a Tribometer Cameron Plint TE 77 (Figure 4) with stainless-steel ball bearings (X105CrMo17) oscillatory sliding against a stainless-steel disc (X105CrMo17). The discs were hardened to $60 \mathrm{HRC}$ with a roughness of $0.05 \mathrm{~mm}$. All the tests were made in a period of 3 hours with a frequency of $5 \mathrm{~Hz}$ at an amplitude of $10 \mathrm{~mm}$ and a total sliding distance of $1080 \mathrm{~m}$.

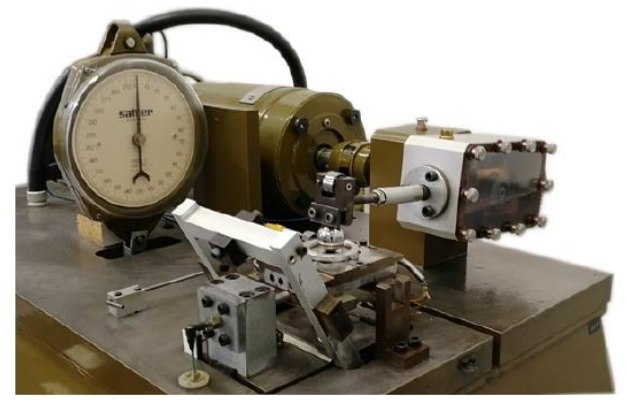

Figure 4: Tribometer Cameron Plint TE 77

\subsection{Hydraulic investigations}

After the selection of a proper material pair from the tribological tests, a new configuration of the sliding material pair in the hydraulic motor was prepared, mounted and investigated on a special hydraulic test rig, shown in Figure 5. The tested hydraulic motor (1) is mechanically connected through a shaft on a precise angular measuring device (3), then on a torque sensor (4) and on the end of the shaft on a hydraulic brake (6). On the hydraulic input and output port are the pressure and temperature sensors (2). The inlet flow was measured with gear-type flow meter (5).

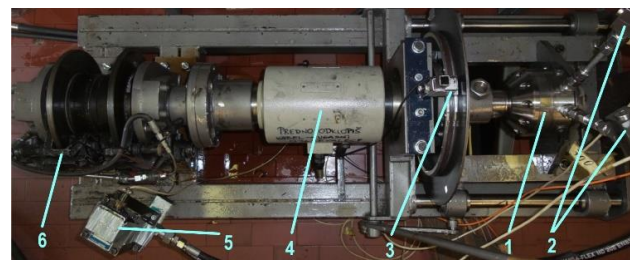

Figure 5: Special hydraulic test rig for hydraulic motor investigations

Figure 6 shows the hydraulic test rig circuit. It contains two different circuits. The main circuit is water hydraulics and is connected to the tested hydraulic motor (3), the second is the mineral oil hydraulics and is connected to an independent hydraulic brake $(4,5)$. The in-line piston water hydraulic pump (1) is driven with a $16-\mathrm{kW}$ electric motor (2). The hydraulic pump (1) sucks the water from the tank (11) and pumps it into a pressure pipe through the pressure-compensated flow-control valve (10) and the flow meter (12). The water is than directed into the $4 / 3$ directional control valve (17) and then into the tested hydraulic motor (3). The rotation direction of the hydraulic motor can be switched forwards and backwards and it is possible to switch off the motor with the directional control valve (17). On the tested hydraulic motor (3) the input and output ports are two pressure sensors (15) and two temperature sensors (16). The return hydraulic line of water is from the hydraulic motor (3) directed through the 4/3 directional control valve (17) and through the return-line hydraulic filter with the $\beta_{3}$ valve higher than 100 back to the water tank (11). The pressure level is protected by the pressure-relief valve (8) at 350 bar. The tested hydraulic motor shaft (3) is mechanically connected to the hydraulic brake (4, 5) through an angular measuring sensor (14) and torque sensor (13). The second hydraulic circuit is designed to control the load - the hydraulic brake $(4,5)$ of the tested hydraulic motor (3). It is totally independent of the water-hydraulics test rig. It uses hydraulic mineral oil (23) to transfer the power from hydraulic oil variabledisplacement axial piston pump (21) powered by the 22-kW electric motor (22) and pumped into the pressure line through the pressure-reducing valve (27) and the $4 / 3$ directional control valve (26) to the cylinder on the hydraulic brake (5). The highest pressure is limited $b$ the pressurerelief valve (24). 


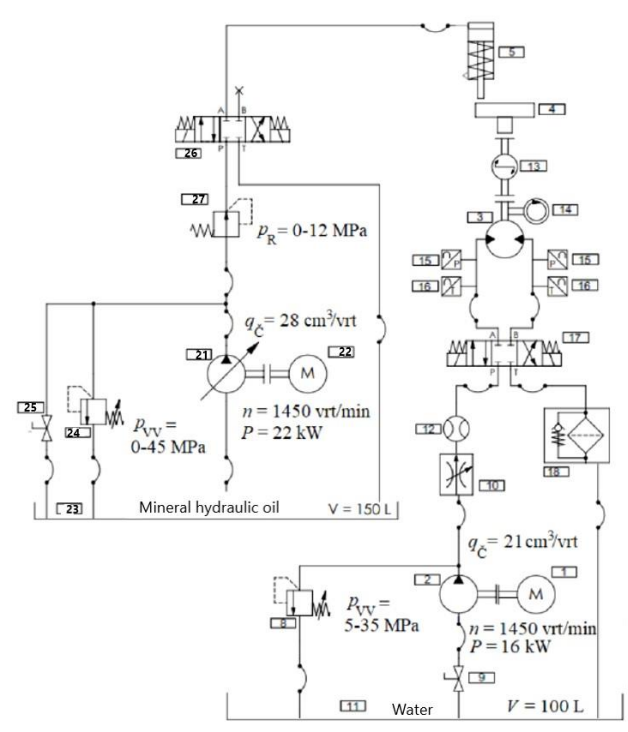

Figure 6: Water-hydraulics test rig for a hydraulic motor

\section{RESULTS}

First we will present the results of the tribological investigations on two different surfaces for three different forces lubricated first with oil and then with water. The results of a real hydraulic test on a hydraulic motor follow.

\subsection{Tribological investigations}

Figure 7 shows the first results of the tribological investigations made on the contact of a stainlesssteel ball against a stainless-steel disc with a hardness of $60 \mathrm{HRC}$ and a surface roughness of $0.05 \mu \mathrm{m}$. The highest coefficient of friction (COF), 0.44 was found with water at a force of $115 \mathrm{~N}$, the lowest COF with water was found at a force of $40 \mathrm{~N}$. The contact of the stainlesssteel/stainless-steel lubricated with mineral hydraulic oil ISO VG 46 gives a more than 6times lower COF than with water under the same conditions (normal force, velocity, material). The highest COF with oil, 0.095 was at a normal force $15 \mathrm{~N}$, the lowest COF, 0.075, was found at a normal force of $115 \mathrm{~N}$.

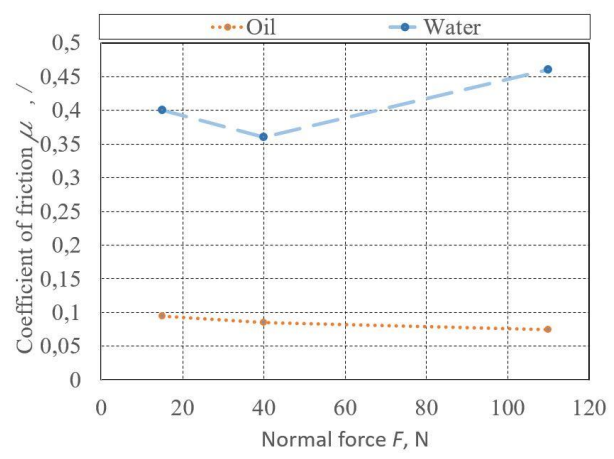

Figure 7: Measured coefficient of friction for stainlesssteel ball and disc, $60 \mathrm{HRC}$ and $0.05 \mu \mathrm{m}$ ( $\mathrm{Ra})$

Figure 8 shows the results of the tribological investigations made on the contact of a stainlesssteel ball against a DLC-coated stainless-steel disc with a hardness of $60 \mathrm{HRC}$ and a surface roughness of $0.05 \mu \mathrm{m}$. The highest coefficient of friction (COF), 0.081, was found with oil at a force of $115 \mathrm{~N}$, the lowest COF with oil was found at a force of $15 \mathrm{~N}$. The contact of the stainless-steel-ball/DLC-coated stainless-steel disc lubricated with water gives between $3 \%$ and $37 \%$ lower COF than with hydraulic mineral oil under the same conditions (normal force, velocity, material). The highest COF with water, 0.069 , was observed at a normal force $15 \mathrm{~N}$, the lowest COF, 0.059 , was found out at normal force of $115 \mathrm{~N}$.

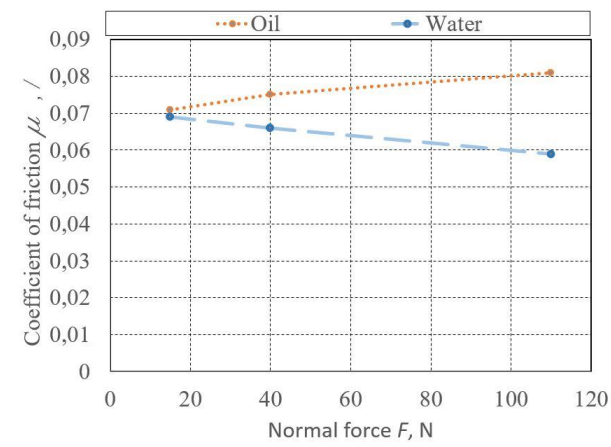

Figure 8: Measured coefficient of friction for stainlesssteel ball and disc with DLC coating, 60 HRC and $0.05 \mu \mathrm{m}(\mathrm{Ra})$

\subsection{Hydraulic}

Figure 9 shows the results for the hydraulic motor with hardened steel contacts lubricated 
with hydraulic mineral oil. The common results show the total efficiency of the hydraulic motor under different working parameters. The best overall efficiency, 0.45 , was observed for pressures higher than $10 \mathrm{MPa}$ and a rotational speed higher than $3 \mathrm{rpm}$. The lowest overall efficiency, 0.15, was found at pressures lower than $10 \mathrm{MPa}$ and rotational speeds higher than 8 rpm.

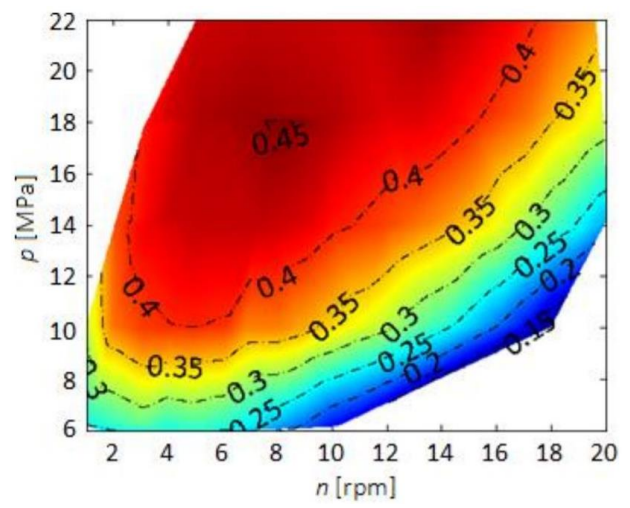

Figure 9: Overall efficiency of gerotor hydraulic motor with hydraulic mineral oil and steel/steel contacts

Figure 10 shows the main results of the real tests on the hydraulic motor tested with hydraulic mineral oil and water. In connection with the tribological tests, real hydraulic test with water also showed a very high COF for the sliding contact of hardened steel against hardened steel. In this case the hydraulic motor did not rotate on the shaft.

After the DLC was applied to the middle element of the gerotor hydraulic motor, the rotorring, its shaft start to rotate and the overall efficiency was $12 \%$. It should probably be higher, but the geometric irregularity did not allow it.

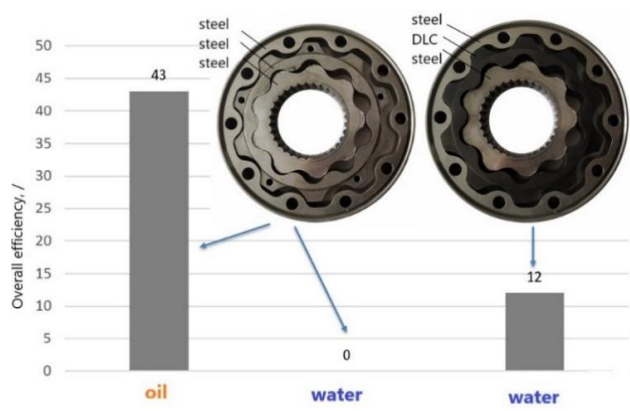

Figure 10: Overall efficiency of gerotor motor with oil (steel/steel), water (steel/steel), water (DLC/steel)

\section{CONCLUSION AND OUTLOOK}

Water hydraulics is one of the possible solutions to prevent environment pollution with harmful hydraulic fluids. An important reason for its nonfrequent use is the leaking of water-hydraulic components. This paper shows the research and development phase of a low-speed and hightorque water gerotor hydraulic motor.

The common conclusions about the waterhydraulics motor are:

- For classic hardened steel materials the coefficient of friction (COF) for water lubrication is up to 6-times higher than the COF in the same contacts lubricated with mineral hydraulic oil.

- The lowest COF, 0.059, in the tribological investigations was for water in the case of a contact with hardened steel against a DLC-coated surface.

- The COFs in water were for DLC from 3 $\%$ up to $37 \%$ lower in water in comparison to oil under the same conditions.

- Steel/steel contacts during lubrication with water do not allow the hydraulic motor shaft to rotate due to a too high COF.

- The tribological contacts of DLC/steel are a promising solution to give a chance for the poorer lubrication of water under higher surface loads. In this case the waterhydraulics motor work with an overall efficiency of $12 \%$. 


\section{NOMENCLATURE}

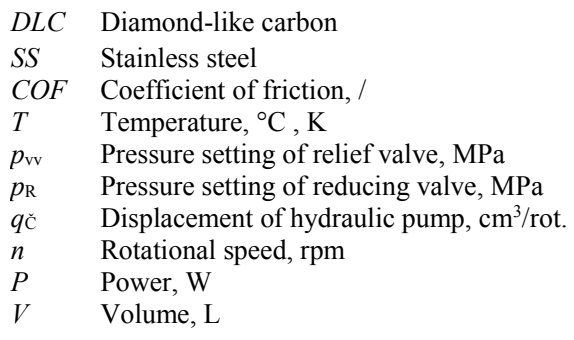

\section{ACKNOWLEDGEMENTS}

For the full support of this research the author is sincerely grateful to Prof. Dr. Mitjan Kalin, Head of TINT. For technical support the author is grateful to Ervin Strmčnik and Rok Jelovčan.

\section{REFERENCES}

[1] Kalin M, Vizintin J (2006) A comparison of the tribological behaviour of steel/steel, steel/DLC and DLC/DLC contacts when lubricated with mineral and biodegradable oils. Wear 261:1,2231.

[2] Kambič M, Kalb R, Tič V, Lovrec D (2018) Compatibility of ionic liquids with hydraulic system components. Advances in production engineering \& management, ISSN 1854-6250, vol. 13, no. 4, 492-503,

[3] Trostmann E (1996) Water Hydraulics Control Technology, Lyngby, 1996, Technical University of Denmark, ISBN: 0-8247-9680-2.

[4] Majdic F (2010) Voda kot kapljevina v pogonsko-krmilni hidravliki (doctoral disertation), Water as a hydraulic pressure medium, Faculty of mechanical engineering, University of Ljubljana, Slovenia.

[5] Koskinen K, Leino T, Riipinen H (2008) Sustainable development with water hydraulics - possibilities and challenges," Proceedings of the 7th JFPS Interantional Symposium in Fluid Power, 2008, Toyama, Japonska, Vol. 1, pp. 11 $-18$.

[6] Gamez-Montero P J, Codina E, Castilla R (2019) A Review of Gerotor Technology in Hydraulic Machines, Energies, 12 (12), 1-44.

[7] Strmcnik E, Majdic F, Kalin M (2019) Waterlubricated behaviour of AISI 440C stainless steel and a DLC coating for an orbital hydraulic motor application. Tribology International $131 \mathrm{pp}$.
$128-136$.

[8] Kano M (2015) Overview of DLC-Coated Engine Components. V: S. Cha, A. Erdemir (ur.): Coating Technology for Vehicle Applications. Springer, Cham, 2015, pp. 37-62.

[9] Ohana T, Suzuki M, Nakamura T, Tanaka A, Koga Y (2004) Tribological properties of DLC films deposited on steel substrate with various surface roughness. Diamond and Related Materials 13:11 pp. 2211-2215.

[10] Trostmann E, Frolund B, Elesen B H, Hilbrecht B (2001) Tap Water As A Hydraulic Pressure Medium, Marcel Dekker, New York, 2001. 